\title{
Visualization and quantification of plankton and detritus using digital confocal microscopy
}

\author{
Peter G. Verity*, Thomas M. Beatty, Samanthia C. Williams
}

Skidaway Institute of Oceanography, 10 Ocean Science Circle, Savannah, Georgia 31411, USA

\begin{abstract}
The application of digital confocal microscopy to studies of plankton and detritus is described. Plankton cells are fluorescently stained using DAPl and proflavin according to established procedures, while detritus is uniquely stained with DAPI and propidium iodide using a recently published companion protocol. Stacks of digitized images of plankton and detritus are acquired in 3 dimensions (3D) using an integrating color charge-coupled device (CCD) mounted atop a fluorescence microscope. A desktop computer drives a $z$-axis motorized controller to optically section plankton cells and detritus at very fine intervals (as small as $1 \mu \mathrm{m}$ or less). Out-of-focus haze associated with each optical slice is removed via a nearest-neighbor algorithm in a process termed deconvolution. Image sets containing these stacks of deconvolved optical slices are subsequently displayed in 3D by volume-rendering software operating aboard a graphics computer. Since the exact $x / y / z$ dimensions of each 3D picture element, or voxel, are known, the volume of plankton or detritus can be calculated. A procedure is described whereby the volume of detritus can be converted to units of carbon and nitrogen. This approach, combined with more traditional $2 \mathrm{D}$ image analysis of plankton communities, offers the first opportunity to separately quantify the pool sizes of plankton and detritus in aquatic ecosystems.
\end{abstract}

KEY WORDS: Plankton - Detritus - Propidium iodide DAPI - Image analysis · Confocal microscopy

\section{INTRODUCTION}

Several microscopic techniques are available for the study of plankton, including brightfield/darkfield, fluorescence, and electron microscopy. Typically these are used for one or the other of 2 applications: to visualize (e.g. Friedman \& Strickler 1975) or to measure (e.g. Verity \& Sieracki 1993) plankton. While combinations of both visualization and quantification have occasionally been accomplished (Taniguchi \& Takeda 1988), generally the ability to display information which relates to taxonomy or morphology while resolving details which relate to abundance or biomass are logistically in conflict. A relatively new tool called confocal microscopy, developed primarily for biomedical sciences, holds considerable promise for simultaneous visualization and measurement with greater resolution (Arndt-Jovin 1991, Bundy \& Paffenhöfer 1993); here we describe digital confocal microscopy for smaller single-celled plankton.

•E-mail: peter@skio.peachnet.edu
Whether the approach is biogeochemical or organismal, the focus of upper water column studies is typically on the living components because of the primary role of plants in the transformation of dissolved inorganic carbon into organic carbon, and because plankton provide the basis for most food webs in the sea. However, the estimated biomass in the sea of nonliving particulate organic matter (POM), or detritus, often exceeds that of plankton in both coastal and open waters (Smetacek \& Hendrikson 1979, Gassmann \& Gillbricht 1982, Andersson \& Rudehall 1993, Caron et al. 1995), and may approach the generally considered value of being $10 \times$ greater than living POM (Pomeroy 1980). The size of this nonliving pool has long been recognized as a problem in phytoplankton research, because detrital carbon 'contaminates' estimates of phytoplankton carbon in field samples from total particulate organic carbon (POC), and relatively 'pure' measures of phytoplankton biomass such as chlorophyll a cannot be used to estimate phytoplankton carbon because the algal $\mathrm{C}$ :chl a ratio varies with algal physiological state and recent nutrient and light history (Banse 1977). 
Models of carbon flow indicate that perhaps as much as half of the primary production on continental shelves could pass through detritus and still support all the major trophic groups, albeit with transfer efficiencies of 20 to $30 \%$ instead of $10 \%$ (Pomeroy 1979 ). Moreover, pools of dissolved organic carbon (DOC) are generally considered to be $10 \times$ greater than those of detritus, and transformations between DOC and detritus occur via microbial exopolymers (Decho 1990). Detritus, therefore, interacts actively with both living POC stocks and DOC pools, and it would seem difficult to quantify or predict carbon (or nitrogen) fluxes without detailed knowledge of detritus biomass and dynamics.

To date, independent direct estimates of detrital biomass have been generally unsuccessful and fraught with contamination (Gordon 1970, Reiswig 1972). Direct measurement of detritus would not only allow more accurate estimation of phytoplankton C:chl a, but also provide data on repository sizes of a POC component which is considered to be a major conduit between living POC and DOC. 'It would be desirable to obtain a better supported conversion factor from ... organic volume to carbon content. ... [N]ew field studies ... should focus on [microscopically derived detrital carbon]...' (Banse 1977, p. 209-210).

If the desired goal is a chemical quantitation of detritus, 2 approaches are theoretically possible: (1) physically isolate detritus and measure its composition directly, and (2) measure a proxy of detritus within a whole water sample and subsequently convert to composition. The first problem has to date proven insoluble, simply due to the large size range of detrital particles: centrifugation or size fractionation is not feasible, if only because bacteria and plankton overlap with the sizes of detrital particles. The second approach has been historically difficult for several reasons. While detritus stains well with alcian blue, which is specific for polysaccharides (Parker \& Diboll 1966), and can be visualized under brightfield microscopy, plankton cells are also stained blue and cannot be distinguished from detritus. With the advent of fluorescence microscopy, plankton could be visually recognized, but 2 problems remained: (1) how to selectively stain detritus distinct from plankiun, dnci (2) how to quantiry an amorphous 3-dimensional (3D) structure using optical techniques which produce a 2-dimensional (2D) image, i.e. standard microscopes? We pursued these questions by expanding upon techniques and experience gained from years of analysis of natural plankton communities using imaging cytometry. The methods for staining plankton and detritus are described elsewhere (Williams et al. 1995); here we present a procedure to render stained plankton cells and detritus in 3D and to quantify their volumes and carbon/nitrogen contents.

\section{MATERIALS AND METHODS}

Sample collection. The samples which were quantitatively analyzed for their carbon pool sizes of plankton and detritus, using the procedures described below, were derived from Niskin bottle vertical profiles at 2 stations in Virginia (USA) shelf waters in May 1993. The RV 'Gyre' provided water from 8 depths at Stn 8 $\left(35.50^{\circ} \mathrm{N}, 74.99^{\circ} \mathrm{W}\right.$, depth $\left.=42 \mathrm{~m}\right)$ and 7 depths at Stn $31\left(36.50^{\circ} \mathrm{N}, 75.31^{\circ} \mathrm{W}\right.$, depth $\left.=39 \mathrm{~m}\right)$. These 2 stations, which were ca $100 \mathrm{~km}$ distant and were sampled $2 \mathrm{~d}$ apart, were selected for analysis because they contained very different algal communities: one dominated by diatoms with high chl a (4 to $12 \mu \mathrm{gl}^{-1}$ ) and the other by photosynthetic nanoplankton with low chl a $\left(<1 \mu \mathrm{g} \mathrm{l}^{-1}\right)$ (Verity et al. 1996).

The steps involved in optically 'capturing' and displaying plankton cells and detritus were identical, and as described below they were interchangeable. The procedures, however, differ for plankton and detritus in (1) those steps prior to display and (2) converting volume measurements to units of biogeochemical significance, e.g. carbon or nitrogen. (1) Plankton cells were stained with single or multiple stains, to highlight external morphological features or subcellular components, and visualized using light or fluorescence microscopy, whereas detritus was stained to fluoresce a single color uniquely different from all plankton. (2) Procedures for measurements of the volume of plankton cells and detritus were unique to each; conversion of volume to carbon/nitrogen for plankton was derived from empirical measurements using laboratory cultures, whereas detrital volume to carbon was derived from natural suspended material, and thus was corrected for the separate contributions of detritus and plankton.

To facilitate understanding of these related analyses, the procedures are described as follows: separate staining of plankton and detritus; 'capture' and display of images of both components; and separate analyses of object volume and conversion to carbon/nitrogen.

Sample staining. Plankton: Samples in the present study were stained with dual fluorescent dyes according to generally used procedures for identifying autotrophic ceils as distinct from heterotropnic or mixotrophic cells (Verity \& Sieracki 1993). Samples were initially fixed with glutaraldehyde $10.3 \%$ final concentration), stained with DAPI $\left(10 \mu \mathrm{g} \mathrm{ml}^{-1}\right.$ final concentration) for $4 \mathrm{~min}$, then momentarily stained with proflavine (1.4 $\mu \mathrm{g} \mathrm{ml}^{-1}$ final concentration), and finally collected on black $0.4 \mu \mathrm{m}$ Nuclepore filters. Filters were covered with a small drop of low-fluorescence immersion oil and a coverslip, and slides were used immediately or stored frozen. Proflavine and DAPI are ideal stains for image analysis of plankton due to their 
bright fluorescence. Depending upon external or internal features of interest, these stains could be supplanted by others or by molecular probes.

Detritus: Our approach was to selectively label detritus and plankton in a water sample using sequential application of glutaraldehyde and dual fluorescent stains, and then concentrate the detritus on $0.4 \mu \mathrm{m}$ black Nuclepore filters as is typically done for plankton enumeration. We tested the efficacy of dozens of combinations of stains, excitation sources, and filter sets (Williams et al. 1995). The optimal combination proved to be propidium iodide (PI) followed by DAPI, in conjunction with UV filters. Under wideband UV excitation, $\mathrm{PI}$ in the presence of glutaraldehyde stained detritus red, while DAPI stained it yellow; combined they produced a deep orange color. The brilliant blue/white fluorescence of DNA associated with bacteria and the nuclei of larger plankton, and induced by DAPI, was spectrally distinct and much brighter than detritus. PI stained cytoplasm of plankton cells a light pink, very similar to the color associated with the autofluorescence of chlorophyll under UV excitation, so that autotrophic, heterotrophic, and mixotrophic cells could not be discriminated from one another, but they were all distinct from detritus. The color difference between glutaraldehyde-fixed previously living plankton, which was light pink, and glutaraldehyde-fixed nonliving detritus, which was deep orange, is apparently due to increased (yellow) staining by DAPI of macromolecules other than nucleotides in detritus (see 'Discussion'). We also confirmed that, subsequent to cell death (defined as disappearance of chlorophyll autofluorescence in phytoplankton), cytoplasm of eucaryotic plankton shifted to the orange color of detritus in natural seawater samples. Living and nonliving bacteria could not be distinguished by this PI/DAPI technique, as reported elsewhere for DAPI (Zweifel \& Hagström 1995); we are developing a separate procedure using rRNA probes to distinguish metabolically active from inactive bacteria (Williams et al. 1996).

Image capture and volume rendering: The heart of the imaging system used here was that described by Verity \& Sieracki (1993), with contemporary upgrades and features required for digital confocal microscopy. Basically, a powerful desktop computer (Pentium $100 \mathrm{MHz}$ with $32 \mathrm{MB}$ RAM and $1 \mathrm{~GB}$ hard drive) housed several integrated software packages which operated microscope-mounted hardware and additionally performed image processing functions. An Olympus BX-60 fluorescence microscope provided a high quality initial view of the sample, and a range of objectives (10 to $100 \times$ ) optimized sample display. An Optronics DEI-470 integrating $2 / 3$ " CCD captured an analog RGB color image at variable frame rates from $1 / 10000 \mathrm{~s}$ to $2 \mathrm{~min}$. An on-board frame grabber continu- ously displayed full-frame images, with integration times up to 2 min producing a minimum sensitivity of 0.0025 lux. An integrated imaging software package, Image Pro Plus (IPP) for Windows (Media Cybernetics, Inc.), controlled image capture, enhancement, measurement, analysis, and output. IPP directed an electronic shutter mounted in-line in the microscope lightpath so that the sample was exposed to excitation for only as long as the camera shutter was open, thus minimizing photobleaching. Images were digitized via an ImaGraph ImaScan/Chroma PCI video capture board and displayed on a Nokia $17^{\prime \prime}$ RGB monitor. Through customized macros, IPP also controlled the $z$-axis motorized stage on the BX-60 and associated modular automation controller (described below).

Plankton or detritus samples were stained and collected on filters as described above. The microscope operator interacted with IPP to set the upper and lower focal planes which comprise the top and bottom optical slices of the object of interest, and to set the distance between slices, which decreases with increasing numerical aperture of the microscope objective. The interslice distance for a $60 \times, 1.4 \mathrm{NA}$ oil objective is $0.5 \mu \mathrm{m}$ (see 'Discussion'). IPP then drove the $z$-axis motorized stage so that the microscope automatically focused on the top of the object, the shutter opened electronically (i.e. no vibration), the CCD grabbed an image (an 'optical slice') during the period when the camera shutter was open (e.g. $1 / 30$ s), the electronic shutter closed, the motorized microscope stage moved down an exact prescribed amount so that a new 'slice' was in focus, and the procedure was repeated until the bottom of the object was reached.

The next step was to mathematically remove the out-of-focus haze from the set of image slices using a software program called Micro-Tome (Vaytek, Inc.). Nearest-neighbor algorithms were applied to individual images or to the entire image set, in a process termed deconvolution, to remove out-of-focus blur; these algorithms have the same effect as pinhole apertures in laser scanning confocal microscopes (see 'Discussion').

The resulting sharply focused optical slices were fed into a graphics computer (Silicon Graphics Iris R4000 Indigo 2, $50 \mathrm{MHz}$, $64 \mathrm{MB}$ RAM, $1 \mathrm{~GB}$ hard drive, 19" monitor), running a volume rendering software package, VoxelView Ultra (Vital Images, Inc.). VoxelView's volume rendering technique represents objects as collections of 3D picture elements, called volume elements or voxels. Each voxel, which is a sample of the original volume and is identified by $x^{-}, y^{-}$, and $z^{-}$ coordinates, has the value of some measured property of the original object like intensity or color. Provided with the $x^{-}, y^{-}$, and $z$-axis dimensions, determined by microscope calibration using IPP, VoxelView interpolated between the image planes and rendered each 
imageset as a 3D object. One of the significant features of VoxelView is that it can calculate the number of voxels in a 3D volume, or any subvolume thereof, which have corresponding properties. A typical $640 x$ 480 pixel image containing 20 slices is composed of a total of 6.1 million voxels. Since the exact size of each voxel in $x^{-}, y-$, and $z$-dimensions was known (e.g. $0.26 \times 0.21 \times 0.50 \mu \mathrm{m}$ at $600 \times$ magnification), the volume in $\mu \mathrm{m}^{3}$ corresponding to those voxels could be calculated, e.g. the volume of chloroplasts within a diatom, or of a bolus of detritus. The computational speed and design of VoxelView Ultra running on an R4000 SGI rendered 6 million voxels in ca 1 s, so that smooth animation sequences were composed to visualize the object from any elevation, azimuth, proximity, contrast, or transparency.

Carbon content. Plankton: The objective in the present study of using digital confocal microscopy in plankton research was the insight offered by visualization in 3D. For rapid quantitation of carbon content of small plankton cells, a better procedure was measurement in 2D, with calculation of the third dimension and subsequently of cell volume (Verity \& Sieracki 1993, and below). Carbon content was then estimated directly using empirically derived equations (Verity et al. 1992, Montagnes et al. 1994).

Detritus: Once the volume of detritus in a sample was determined using the confocal microscope approach described above, 4 steps were necessary to calculate the carbon/nitrogen content. The total amount of POC in a water sample was measured chemically, the amount of plankton carbon/mitrogen was measured microscopically, the amount of detrital carbon/nitrogen was calculated by difference, and detritus volume was regressed against detritus carbon/nitrogen to develop a predictive regression. These steps are described below in sequence.

(1) Total POC and PON were measured by combustion in a commercial CHN analyzer according to standard methods (Sharp 1974). Basically, samples were filtered at low vacuum pressure onto pre-combusted $\left(450^{\circ} \mathrm{C}\right.$ for $\left.4 \mathrm{~h}\right) 25 \mathrm{~mm} \mathrm{GF} / \mathrm{F}$ filters, avoiding obvious sources of contamination. These were transferred onto similarly pre-combusted foil storage sheets, and stored trozen $\left(-70^{\circ} \mathrm{C}\right)$ until analyzed. After freeze-drying, they were combusted in a CHN analyzer using acetanilide standards, and corrected for equal volume media blanks.

(2) The methods used to determine the biovolume of plankton cells via image analysis techniques, and subsequent conversion to cell carbon and nitrogen, have already been developed and tested (Sieracki et al, 1989a, b, Verity et al. 1992, Verity \& Sieracki 1993), and were described above under 'Sample staining' Plankton cells were analyzed using an imaging cyto- metry system which was a subset of the one described for confocal research. For quantitative enumeration and sizing of plankton, an image was located, either randomly or on a transect (see below), and focused on the video monitor visually. It was then rapidly digitized into the computer, avoiding significant fluorescence fading. The color video system used real-time frame averaging to reduce noise. At this point, the image was edited if necessary, e.g. to separate adjoining cells. Once the image was judged to be adequate either the whole image was analyzed or individual cell subimages were saved for later analysis. Two approaches were used depending upon the density on the slide of the particular cell population being analyzed. For cells which were numerous per field and relatively uniform in brightness in a given sample (e.g. cyanobacteria and some flagellates), randomly chosen whole fields were analyzed. In this case all the cells in a field were segmented (identified in the image) and measured automatically. This approach required that a single threshold be used for all cells in the image, but it was faster than automatically finding individual cell thresholds. Analysis of an image with 40 cells took about $4 \mathrm{~s}$.

For more rare cells, transects of the slide were scanned and individual cells were isolated and identified by the operator interactively. In this way densities of rare cells were calculated per volume of sample. By interfacing the motorized stage and associated modular automation controller with the epifluorescence microscope, the operator scanned transects of variable length across the plankton slides while the computer recorded the fraction of the surface area of the slide which has been examined. For abundant populations, the computer randomly selected individual locations on the slide. The driver software was modified so that the entire process (moving to a given location, focussing, opening an electronic shutter, grabbing an image, closing the shutter, and moving to a new location) was automated and computer-controlled. Subimages containing the individual cells were temporarily stored and analyzed automatically overnight. The analysis procedure for these sub-images involved automatic threshold determination using the second derivative method (Sieracki et al. 1989a), segmentation and cell measurement. Cell measurement data and example images were archived on tape or floppy disk for later analysis. Individual cell biovolume measurements (Sieracki et al. 1989b) were converted to carbon/ nitrogen biomass using conversion factors based on literature values of carbon/nitrogen density or C:N ratios (Bratbak \& Dundas 1984, Verity \& Langdon 1984. Børsheim \& Bratbak 1987, Putt \& Stoecker 1989, Lessard 1991, Verity et al. 1992, Kroer 1994). The abundance, size, and biomass of crustacean zonplankton were measured according to Verity et al. (1996). 
(3) The carbon/nitrogen content of detritus was calculated as the difference between total combusted POC/PON and that contained in bacteria, eucaryotic and procaryotic phytoplankton and protozoan and metazoan zooplankton. Many bacteria in field samples, where they typically comprise $<5$ to $10 \%$ of total POC in shelf environments (Smetacek \& Hendrikson 1979, Verity et al. 1996), may pass GF/F filters (manufacturers claim $98 \%$ retention of $0.7 \mu \mathrm{m}$ particles; see also Altabet 1990), so their contribution to combusted POC/PON should be minimal. However, many were captured on $0.4 \mu \mathrm{m}$ Nuclepore filters and thus contributed to estimated plankton carbon and nitrogen. This was corrected for by enumerating and sizing bacteria via image analysis in whole water samples prior to filtering the POC/PON samples, and again in the filtrate.

(4) The calculated detrital carbon/nitrogen from each sample was then compared to the measured volume of detritus in that sample to determine the detritus carbon:volume and nitrogen:volume conversion factors.

\section{RESULTS}

\section{Plankton}

The first test of the ability of digital confocal microscopy was to confirm that it accurately represented the size and shape of known objects. Latex microspheres of various diameters were imaged as described in the 'Materials and methods', and 3D volumes were compared to those calculated from diameter dimensions applied to mensuration equations (Table 1). (The coefficient of variation of the diameter of latex microspheres decreases with increasing bead size, and is typically $1 \%$ or less for beads $10 \mu \mathrm{m}$ or larger; Polysciences, Inc., Warrington, PA, USA.) For beads spanning the sizes of many unicellular plankton ( 6 to $20 \mu \mathrm{m}$ ), beads rendered by VoxelView showed only minor deviations from sphericity, and the 2 methods yielded similar estimates of volume. For beads

Table 1. Volumes of fluorescent latex microspheres calculated directly from diameters and from images rendered as 3-dimensional objects

\begin{tabular}{|ccc|}
\hline $\begin{array}{l}\text { Bead dia- } \\
\text { meter }(\mu \mathrm{m})\end{array}$ & $\begin{array}{c}\text { Calculated } \\
\text { volume }\left(\mu \mathrm{m}^{3}\right)\end{array}$ & $\begin{array}{c}\text { Rendered } \\
\text { volume }\left(\mu \mathrm{m}^{3}\right)\end{array}$ \\
\hline 6.0 & $1.13 \times 10^{2}$ & $1.05 \times 10^{2}$ \\
10.0 & $5.24 \times 10^{2}$ & $5.39 \times 10^{2}$ \\
20.0 & $4.19 \times 10^{3}$ & $4.06 \times 10^{3}$ \\
45.0 & $4.77 \times 10^{4}$ & $5.41 \times 10^{4}$ \\
90.0 & $3.82 \times 10^{5}$ & $4.49 \times 10^{5}$ \\
\hline
\end{tabular}

$45 \mu \mathrm{m}$ and larger, volumes derived by 3D imaging were larger than those calculated from measured diameters. Visual inspection of the rendered volumes of larger beads showed shape distortions in the lower portion of the bead, specifically that the lower portion of the bead was not spherical but rather was elliptocylindrical. This effect was apparently caused by the thickness or opacity of these larger specimens and the inherently lower resolution in the $z$-axis dimension (see 'Discussion', and Russ 1995, Chap. 9).

Plankton cells in the size range of ca 5 to $20 \mu \mathrm{m}$, fluorescently stained with DAPI and proflavin, were faithfully rendered in 3D; an example of Thalassiosira $\mathrm{sp}$. is illustrated in Fig. 1. The cell was imaged under blue excitation using an infinity-corrected $60 \times$ Plan Apochromat oil immersion objective, NA 1.40. The valve diameter of this cell was measured as $21.4 \mu \mathrm{m}$. It was then optically sectioned at $0.50 \mu \mathrm{m}$ intervals, resulting in 43 'slices'. After the image set was acquired, the coverslip on the oil embedded filter holding the plankton cell was moved laterally, displacing the Thalassiosira sp. cell into girdle view. Cell thickness was measured at $6.9 \mu \mathrm{m}$. The image set was rendered by VoxelView, with 1 interpolated slice inserted between each measured slice to account for the $50 \%$ lower $z$-axis resolution. The resulting $3 \mathrm{D}$ image of the cell (Fig. 1) was $7.2 \mu \mathrm{m}$ thick. The cell volume calculated from direct linear dimensions and assuming a right circular cylinder shape (volume $=\pi r^{2} h$ ) was $2482 \mathrm{\mu m}^{3}$. The volume calculated by VoxelView was $2589 \mu^{3}$, or $4 \%$ greater than that calculated from length and depth. The volume of the cell which corresponded to the autofluorescence of chloroplasts was $596 \mathrm{\mu m}^{3}$, or $17 \%$ of the total cell volume; cytoplasm and nucleus comprised 50 and $7 \%$ of total cell volume, respectively.

The sequence of images in Fig. 1 are individual 2D images taken from a 3D animation of Thalassiosira sp. created by VoxelView and serve to illustrate the power and options of visualization. The initial view, which is at a slight angle to the $z$-axis plane, shows a brilliant white/yellow nucleus stained by DAPI, orange/pink autofluorescence of chloroplasts, and blue/green cytoplasm stained by proflavin, viewed against a black Nuclepore background. In subsequent images, voxels corresponding to the nucleus have been removed for clarity. The presence of black within the cell signifies the absence of any fluorescing cellular material, and presumably corresponds to the diatom vacuole. The frustule is not visible in this stained preparation, but can be simultaneously visualized by combining minimal darkfield illumination with blue wavelength fluorescence excitation. As the animation proceeds from left to right, the cell gradually rotates in that direction through $360^{\circ}$. Concurrently, VoxelView was instructed 


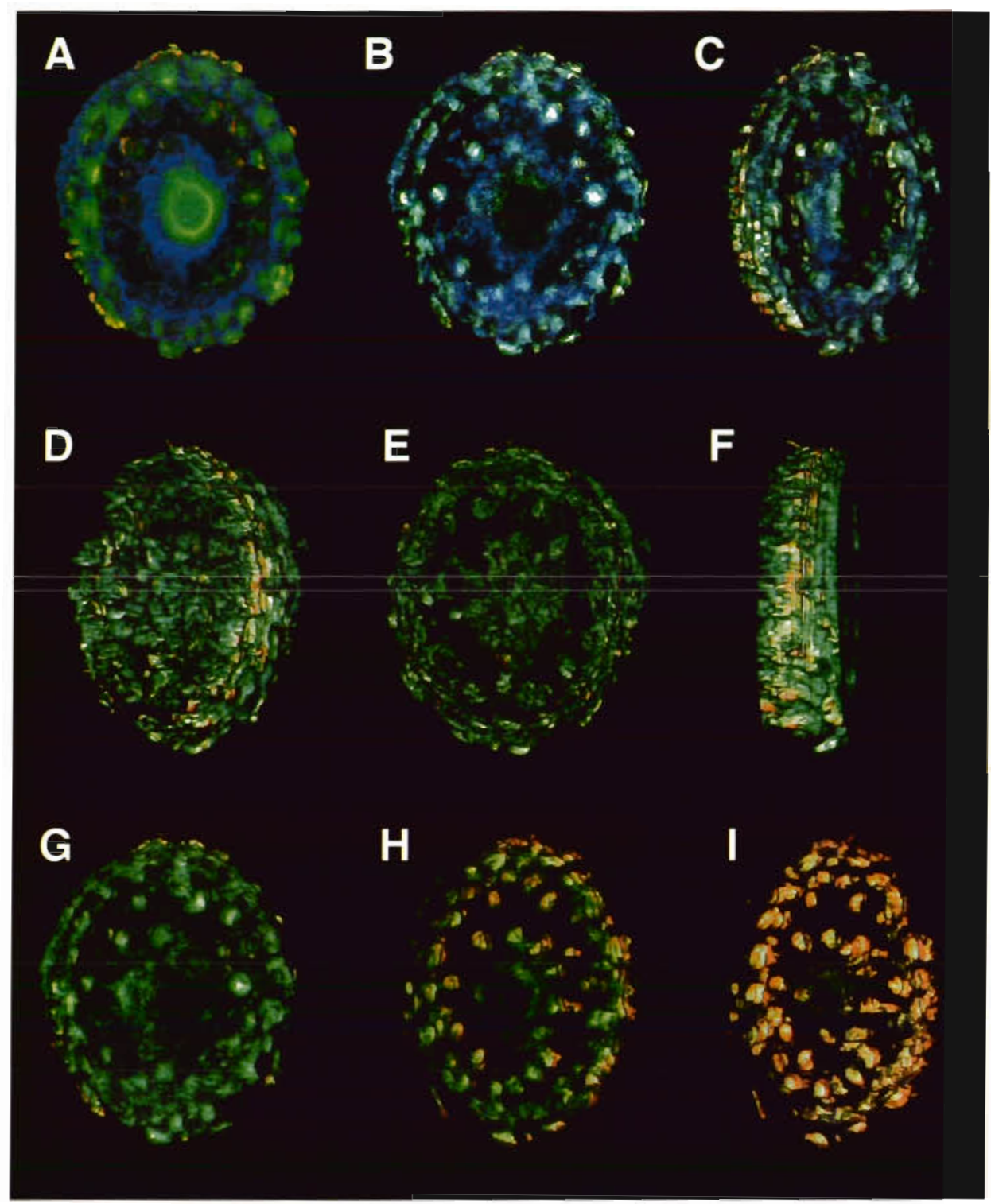

Fig. 1. Sequence of images from a computer animation of a single cell of Thalassiosira $\mathrm{sp}$. Blue/green voxels are those portions of the cell stained by proflavin, i.e. cytoplasm. Pink/ orange voxels are those portions of the cell which autofluoresce, i.e chloroplasts. The intense white/yellow voxels in the cel] center, which represent the DAPI-stained nucleus, were removed in images after the initial one, to illustrate the ability to selectively identify subregions of an object of interest. Proceeding from the upper left panel (A) to the lower right panel (I), the cell rotates through nearly $360^{\circ}$

to gradually 'peel away' those voxels corresponding to the blue/green cytoplasm, in order to reveal the number, size, and arrangement of the chloroplasts. Interestingly, the chloroplasts appear first at the girdle region, suggesting that the cytoplasm was thinnest inere. Upon removal of most of the cyiopiasm, it is evident that the chloroplasts were concentrated around the peripheral edge of the cell, with 2 concentric rings of chloroplasts between the outer ring and the central nucleus.

\section{Detritus}

Natural detritus from continental shelf waters concentrated on Nuclepore filters typically collapses down to thicknesses of 5 to $10 \mu \mathrm{m}$ on various sections of the filter. With intervals of $0.5 \mu \mathrm{m}$ between slices, only 10 to 20 optical slices are needed to measure all the detrital particles, compared to often 60 to 80 slices taken at higher magnification when larger (thicker) plankion celis are volume-rendered. Where deirius is thinner (or absent), the upper optical slices (or all slices) contain no detrital particles. The standard protocol described in the 'Materials and methods' can be specifically modified for analysis of detritus. Since the boluses of detritus do not need to be visualized, but only quantified, one can simply measure the number of voxels corresponding to the uniquely stained detritus in each optical slice and, knowing the exact depth of each slice, directly calculate detrital volume. This approach avoids the need to render the object in $3 \mathrm{D}$ 
yet gives identical estimates of volume, which saves time and the need for an expensive SGI graphics workstation. Subroutines were composed in Visual Basic language to accomplish these measurements on the fly as each slice was imaged.

The number of visual fields of detritus which must be analyzed for statistically confident extrapolation to the entire filter varies with the concentration of detritus collected on the filter, but is typically 20 fields. Fewer fields are required than when enumerating plankton cells because so much more detritus occurs per unit surface area of filter. It is best to adjust sample volume to reduce the number of fields required, by previewing initial samples in the microscope.

Measured volumes of detritus from the samples collected in Virginia shelf waters were regressed against calculated detrital carbon and nitrogen (Fig. 2). The linear regression models suggested that detrital carbon was estimated from detrital volume with high confidence as $0.23 \mathrm{pg} \mathrm{C} \mathrm{mm}^{-3}$ detrital volume. Detrital nitrogen was estimated from volume as $0.011 \mathrm{pg} \mathrm{C} \mathrm{mm}^{-3}$, with greater variance. Total POC and nitrogen PON, and those fractions corresponding to living plankton, were also measured in the same samples (Table 2). Plankton POC ranged from 25 to $365 \mu \mathrm{g} \mathrm{C}^{-1}$, while

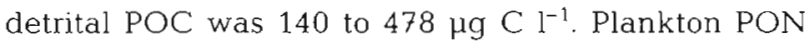
was 4 to $57 \mu \mathrm{g} \mathrm{N} \mathrm{I}^{-1}$ and detrital PON was 5 to $32 \mu \mathrm{g} \mathrm{N}$ $\mathrm{l}^{-1}$. Detrital carbon and nitrogen were not significantly correlated if all data points were included, but exhibited a significant $(\mathrm{p}<0.05)$ linear relationship if the highest carbon data point was excluded from analysis (Fig. 3). Comparing \% detrital POC to the total $P O C: c h l$ a ratio suggested that detritus was the most important carbon depot in high C:chl a waters (Fig. 4). Although preliminary, these data suggest that it may eventually be possible to derive predictive regression
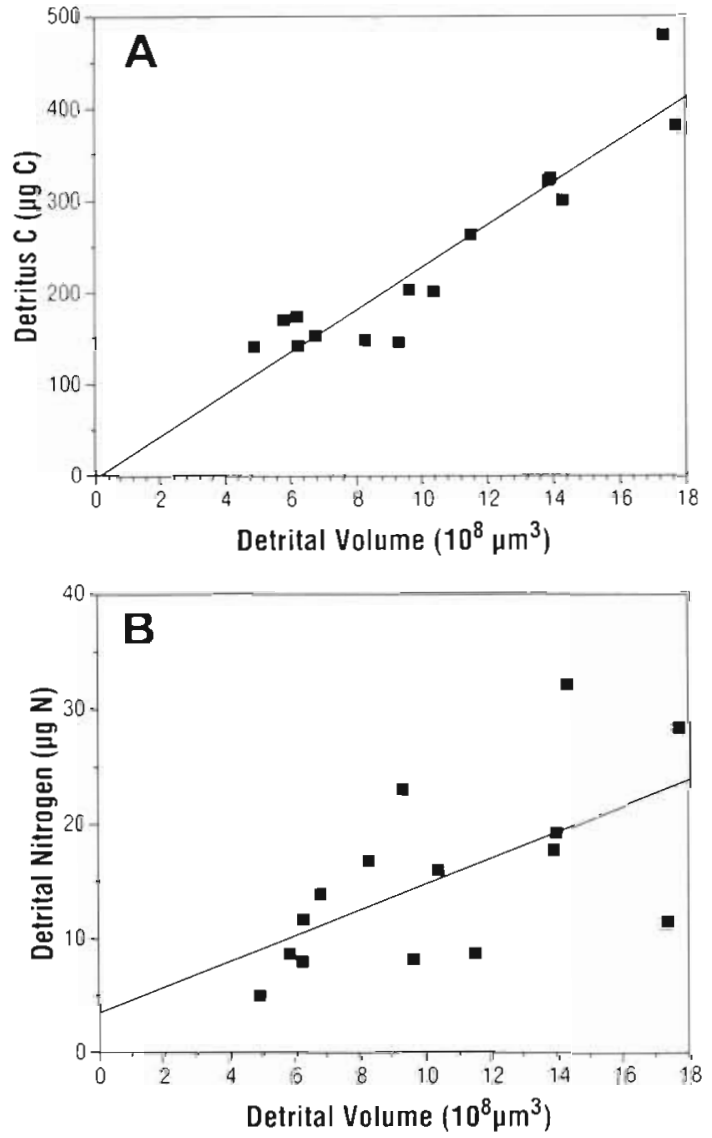

Fig. 2. (A) Relationship between volume of detrital particles measured in 3D and carbon content of detritus estimated from chemical and microscopic measurements. Samples were from 2 vertical profiles in continental shelf waters off Cape Hatteras (Virginia, USA) in May 1993. Model I linear regression $(y=a x+b)$ : detrital carbon $\left(\mu \mathrm{g} \mathrm{l}^{-1}\right)=23.0$ (detrital volume, $\left.10^{8} \mu \mathrm{m}^{3}\right)-3.6, \mathrm{r}^{2}=0.87, \mathrm{n}=15$. (B) As in (A), but for detrital nitrogen. Model I linear regression: detrital nitrogen $\left(\mu \mathrm{g} \mathrm{I}^{-1}\right)=$ 1.1 (detrital volume, $\left.10^{8} \mu \mathrm{m}^{3}\right)+3.5, \mathrm{r}^{2}=0.37, \mathrm{n}=15$

Table 2. Total particulate organic carbon (POC) and nitrogen (PON) and those portions corresponding to living plankton and nonliving detritus. Units are $\mu \mathrm{g}^{-1}$

\begin{tabular}{|c|c|c|c|c|c|c|c|}
\hline Stn & Depth $(\mathrm{m})$ & Total POC & Total PON & Plankton POC & Plankton PON & Detrital POC & Detrital PON \\
\hline \multirow[t]{8}{*}{8} & 5 & 216 & 24 & 75 & 12 & 141 & 12 \\
\hline & 7 & 214 & 24 & 62 & 11 & 152 & 14 \\
\hline & 11 & 207 & 27 & 60 & 10 & 147 & 17 \\
\hline & 16 & 165 & 9 & 25 & 4 & 140 & 5 \\
\hline & 21 & 233 & 21 & 33 & 5 & 200 & 16 \\
\hline & 30 & 370 & 27 & 47 & 8 & 323 & 19 \\
\hline & 35 & 240 & 39 & 95 & 16 & 145 & 23 \\
\hline & 40 & 244 & 15 & 42 & 7 & 202 & 8 \\
\hline \multirow[t]{7}{*}{31} & 3 & 552 & 57 & 172 & 29 & 280 & 28 \\
\hline & 6 & 552 & 55 & 232 & 37 & 320 & 18 \\
\hline & 10 & 656 & 40 & 178 & 29 & 478 & 11 \\
\hline & 15 & 512 & 66 & 213 & 34 & 299 & 32 \\
\hline & 20 & 627 & 65 & 365 & 57 & 262 & 9 \\
\hline & 25 & 502 & 59 & 329 & 51 & 173 & 8 \\
\hline & 31 & 430 & 49 & 261 & 40 & 169 & 9 \\
\hline
\end{tabular}




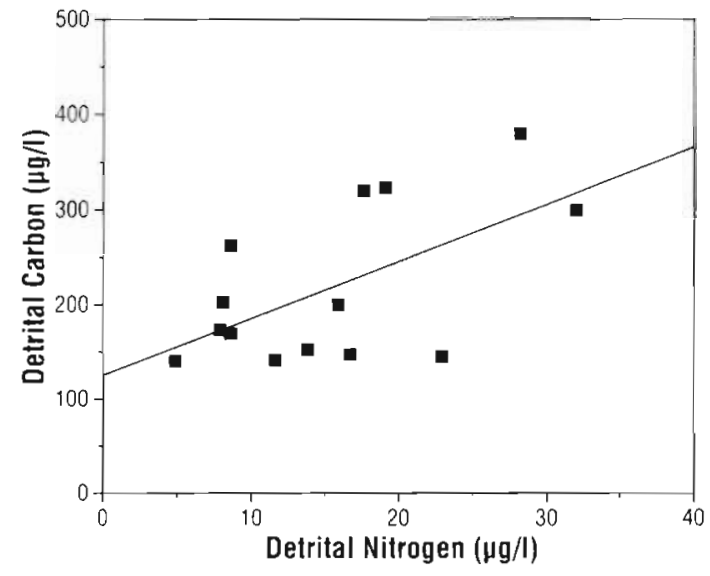

Fig 3. Relationship between estimated detrital carbon and nitrogen for samples in Fig. 2. The Dixon test for outliers (Taylor 1990) supported the elimination (at the $95 \%$ confidence interval) of 1 data point from the linear regression model: detrital carbon $\left(\mu \mathrm{g}^{-1}\right)=6.0$ (detrital nitrogen, $\mu \mathrm{g} \mathrm{l}^{-1}$ )

$$
+125.3, r^{2}=0.35, n=14
$$

models to estimate detrital carbon from total POC (Fig. 5) or estimate plankton carbon from C:chl $a$ or from chl a directly (Fig. 6).

\section{DISCUSSION}

In medicine, 3D visualization is uniquely valuable in the form of CAT scans or tomography, typically done on objects the size of the human body. With plankton, however, the object to be viewed is the size of a red blood cell within the human body, so there is an immense scaling problem. The CCD viewing plankton on the microscope does not use adjustable focussing

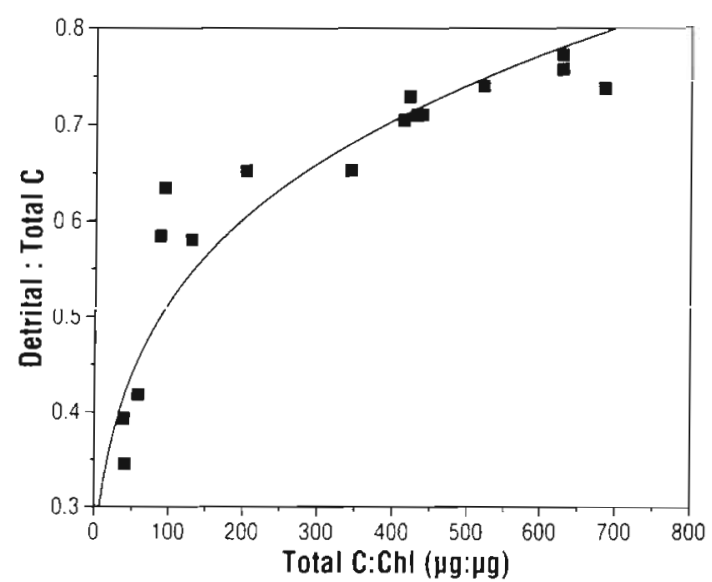

Fig. 4. Relationship between detrital carbon as a fraction of total POC and the ratio of total POC to chl $\alpha_{4}$ in the samples decribed in Fig. 2. Detrital carbon:total carbon = $0.29 \log \left(\mathrm{POC}: \mathrm{chl} \mathrm{a}_{1} \mu \mathrm{g}: \mu \mathrm{g}\right)-0.005, \mathrm{r}^{2}=0.89, \mathrm{n}=15$

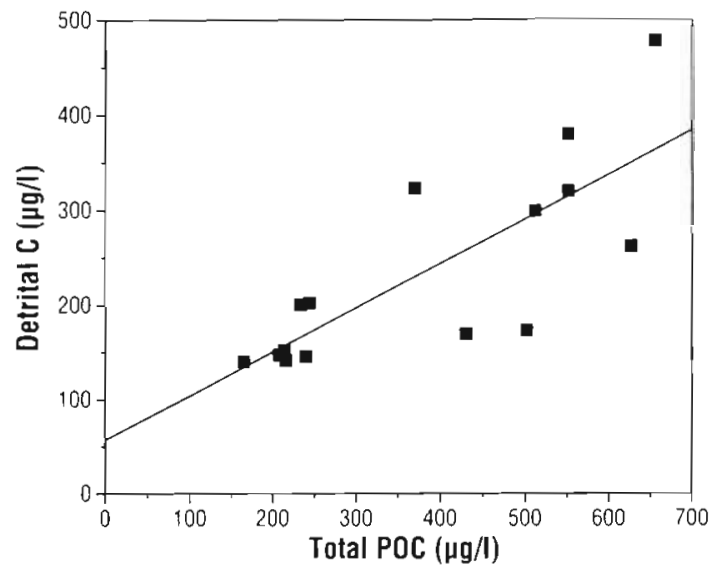

Fig. 5. Relationship between detrital carbon and total POC for samples described in Fig. 2. Model I linear regression: detrital carbon $\left(\mu \mathrm{g} \mathrm{l}^{-1}\right)=0.47$ total POC, $\left.\mu \mathrm{g} \mathrm{l}^{-1}\right)+57.1, \mathrm{r}^{2}=0.61, \mathrm{n}=15$

lenses. By analogy, it would be as though your eyes only focused on objects which were a constant distance away from you, as if everything closer or further away was blurry or out of focus. The solution is to move the microscope stage which holds the specimen closer or further from the CCD in order to focus on it. However, the plane of focus is very thin, e.g. $0.3 \mu \mathrm{m}$ using blue excitation and a $60 \times 1.4$ NA objective, and the other sections of the cell (above and below the plane in focus) are blurry.

To obtain the detailed 2D image slices necessary for high resolution rendered volumes, that out-of-focus light must be removed, and 2 types of methods are available. One is to allow only the light (= image) which is in focus to reach the camera, by forcing it to pass through very tiny pinholes or slits which can be

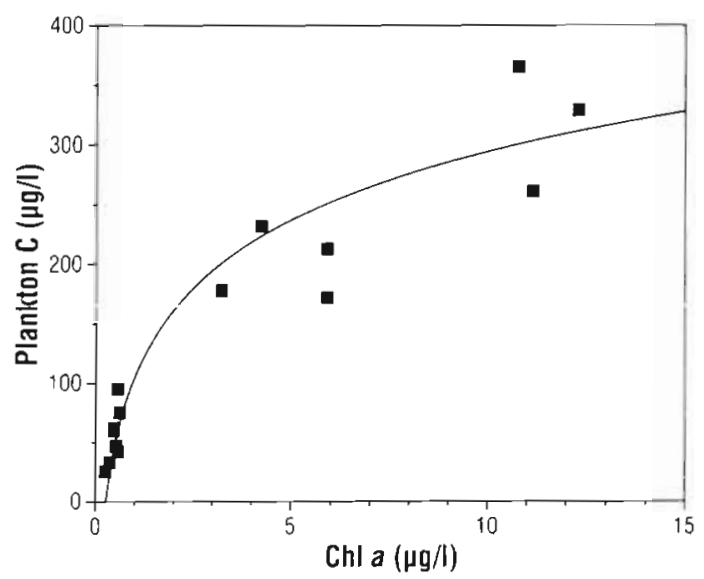

Fig. 6. Relationship between plankton carbon measured by $2 \mathrm{D}$ image analysis and fluorometrically determined $\mathrm{chl} a$ in the samples described in Fig. 2. Plankton carbon $\left(\mu \mathrm{g} \mathrm{l}^{-1}\right)=$ $172.6 \log \left(\right.$ chl $\left.a, \mu \mathrm{g} \mathrm{I}^{-1}\right)+108.4, \mathrm{r}^{2}=0.91, \mathrm{n}=15$ 
set to stop passage of the out-of-focus light. The detriment to this approach is a tremendous (i.e. 95\%) reduction in light intensity coming from the object, so that a substantial excitation light source is required. This is typically a laser, which has 3 undesirable attributes: (1) it emits very high energy which quenches fluorescence; (2) the illuminating beam and return light aperture must be precisely aligned; and (3) it is therefore comparatively quite expensive. Laser-based systems can compensate for intensity reduction by scanning the sample multiple times; they are also generally better for thicker or more opaque specimens (Agard et al. 1989, Rigaut et al. 1992).

The other approach described here, digital confocal microscopy, depends upon the distribution of light energy around a point source, which is theoretically and mathematically well understood (Gibson \& Lanni 1990, Hiraoka et al. 1990). The out-of-focus blur or smear, which is a natural consequence of the optics of a light microscope, is added to the image in a precise and predictable manner by the point spread function (PSF) of the microscope (Young 1989). The software solution used in the present study calculates the PSF using diffraction theory and knowledge of the excitation wavelengths, the numerical aperture of the objective, the $x / y$ dimensions of pixels within each image plane, and the $z$-axis distance between images. Using these data, the digital confocal method uses a nearestneighbor algorithm (Agard et al. 1989) to computationally remove the out-of-focus haze, obviating the need for lasers and allowing samples to be imaged on modified standard microscopes. However, either approach, laser scanning or digital confocal microscopy, will work, and the latter can be used to improve laserderived images.

\section{Plankton}

Confocal microscopy provides several advantages over other methods of visualization of plankton. Because of its extremely narrow focal plane, a light microscope presents a $2 \mathrm{D}$ image to the eye or any other detector, hence the $3 \mathrm{D}$ structure of larger thicker specimens cannot be seen at any one time. Various techniques with light microscopes (e.g. phase contrast, shadow casting, differential interference contrast) provide some depth perception, but not $3 \mathrm{D}$ visualization. Scanning electron microscopy combines superior resolution with depth perception, but it is comparatively costly and cannot resolve internal structure. Only confocal microscopy combines light- or laser-based micrometer-scale resolution with the ability to visualize the plankton cell in 3D. Two particular attributes are salient. One described here is the ability to quantify volumes or subvolumes thereof, e.g. chloroplasts or any other cellular feature which can be uniquely identified. This capability seems particularly promising with the development of specific molecular probes which can be conjugated to a broad color range of fluorescent stains. Another powerful tool is the ability to section a cell in any orthogonal direction, and then visually or quantitatively contrast internal features within and among sections.

While confocal microscopy is particularly well suited for resolving and displaying internal structural features (e.g. Bundy \& Paffenhöfer 1993), it is not presently the optimum tool for rapid estimation of the size or biomass of numerous plankton cells. It requires a skilled operator approximately $1 \mathrm{~h}$ to acquire, deconvolve, and render a plankton cell in $3 \mathrm{D}$. In the same amount of time, hundreds of plankton cells can be measured in $2 \mathrm{D}$ and their volumes estimated from knowledge of the third dimension (Sieracki et al. 1989b, Verity \& Sieracki 1993).

\section{Detritus}

Detritus can be categorized into 2 functional types: relatively large, fast-sinking particles or aggregates, and smaller suspended particles. Because of interest in fluxes to the seafloor, methods for analyzing sinking aggregates have been developed (Alldredge \& Gotschalk 1989, Walsh \& Gardner 1992); these and related studies have confirmed the significance of aggregates to vertical fluxes and as microzones for enhanced plankton activity (Michaels \& Silver 1988). Small detrital particles, however, are equally important, perhaps more so in the context of upper water column dynamics. It is the small well-suspended particles which are captured in Niskin sampling bottles, which end up on GF/F filters, and analysis of which indicates that nonplankton carbon often exceeds the contributions of plankton to total POC, e.g. Eppley et al. (1992). Thus, the working definition of detritus for the purposes of this study, derived from Lenz (1977) and Passow et al. (1994), is non-plankton POC captured in Niskin bottles and collected on $0.4 \mu \mathrm{m}$ polycarbonate filters.

There are essentially 3 steps in the method described here to measure detritus: (1) staining detritus distinct from other inorganic and organic material; (2) measuring the volume of detrital particles; and (3) estimating chemical content from volume. Each of these is discussed below.

Propidium iodide (PI) is generally considered to be a nuclear stain because it strongly stains DNA and RNA and is excluded by living membranes; it is therefore used as a marker for dead cells in laser-based flow cytometry studies. The excitation maxima of PI for such 
applications is $530 \mathrm{~nm}$, but PI also absorbs at short, intermediate, and long UV wavelengths (Taylor \& Lappi 1975). Thus, while PI-stained material fluoresces strongly under green excitation, it fluoresces moderately under wideband UV excitation and emits at wavelengths different than that of DAPI. As a noncovalent intercalating compound, PI inserts itself indiscriminately between nucleotide base pairs, but also electrostatically binds to various macromolecules including proteins, polysaccharides, glycosaminoglycans, and membranes (Arndt-Jovin \& Jovin 1989). While DAPI is most appreciated for binding preferentially to double-stranded DNA, it also binds to polyphosphates, glycoproteins, polysaccharides, various sulfates, sarcoplasmic reticulum, tubulin, and microtubules (Haugland 1992). These are common components of detritus (Mel'nikov 1974, Decho 1990), hence the efficacy of dual PI/DAPI staining (Williams et al. 1995). Proflavin can also be added as a third stain, which has the advantage of allowing measurement of nonliving $P O C$ and discrimination among types of plankton POC on the same samples (using both blue and UV excitation), but the stain time must be watched closely in order to avoid degrading the PI/DAPI effect on detritus. For routine use, it is preferable to make one preparation to distinguish detritus from plankton, and a separate slide to distinguish among the various types of plankton. At present, the operator manually distinguishes detrital particles by color distinction compared to plankton (Williams et al. 1995), but we are developing an automated color separation algorithm as a more objective protocol to minimize inter-operator variance.

Once particles of interest (detrital or otherwise) can be distinguished from others, confocal microscopy provides a unique solution to their quantitation; laser scanning or digital confocal microscopy are both appropriate. The data illustrated here (Table 1, Fig. 1) indicate that digital confocal microscopy captures and renders the volumes of nano- and small microplankton accurately; for detritus, the need to render it in $3 \mathrm{D}$ is secondary to mensuration of volume. The volume measurements require knowledge of the $x / y$ dimensions of the pixels that comprise a $2 \mathrm{D}$ image, which are calibrated directly using a stage micrometer, and the $z$ aris distance between slices. The best possible $z$-axis resolution is defined as the theoretical Rayleigh minimum, which is inversely related to the resolving power of the objective in use according to $D_{\min }=1.22 \lambda / 2 \mathrm{NA}$, where $\lambda$ is the peak wavelength and NA is the numerical aperture of the objective (Shatton 1989): using a 1.40 NA oil objective under $0.5 \mu \mathrm{m}$ illumination, the minimum resolution is $0.25 \mu \mathrm{m}$. The ideal $z$-axis spacing between image planes, according to Nyquist sampling theorem, should be twice the spatial resolution of the optical system (Castleman 1979), or $0.5 \mu \mathrm{m}$ for the 1.4 NA oil objective. Thus the $x / y / z$ dimensions of each voxel corresponding to detritus are known, and with sufficient subsamples of each filter, the volume of detrital particles in a sample can be estimated.

The entire procedure is only as accurate as the conversion factor from volume to carbon or nitrogen (e.g. Caron et al. 1995). This factor (1) may have errors associated with its calculation and (2) may vary naturally. As described here, the concentrations of detrital carbon and nitrogen were derived by subtracting microscopically measured plankton carbon/nitrogen from total POC/PON determined by high temperature combustion. The latter method for total POC/PON is well known. The comparative ease and accuracy of $2 \mathrm{D}$ imaging cytometry to estimate the carbon biomass of mixed plankton communities have been known for some time (Verity et al. 1992, 1993, Sieracki et al. 1993). C:chl a ratios of phytoplankton derived from these measurements fall within the ranges derived from cultures with similar nutrient and light histories (Verity et al. 1996), implying that the estimates of carbon biomass are not wildly inaccurate. Estimates of nitrogen biomass, however, may suffer from reduced accuracy of cell volume to cell nitrogen conversion factors, which are more poorly known than those for carbon.

Since total POC/PON and plankton POC/PON can be measured with acceptable accuracy, then detrital carbon/nitrogen can be estimated by difference. However, if the mass of detritus is quantitatively related to its volume, then detrital carbon and nitrogen can be estimated directly from volume, rather than having to measure both total and plankton POC/PON and calculate by difference. The field data illustrated here imply that conversion from detrital volume to carbon, and to a lesser extent nitrogen, may be robust over mesoscale distances, at least during brief periods in time. However, the net effect of the various processes which produce and decompose material contained in detritus is that the ratio of POC and PON to particle volume $(\mathrm{C}: \mathrm{V}$, $\mathrm{N}: \mathrm{V}$ ) in detritus may or may not be constant. For example, the $C: V$ ratio in detritus may decrease as bacteria and their associated microbial food web disrupt the integrity of the detrital material, enhancing leaching (Diddanda \& Pomeroy 1988): typical degradation rates are 2 to $4 \% \mathrm{~d}^{-1}$ (Biddanda 1988, Seiki et al. 1991, Lee \& Fisher 1992). Alternatively, the $C: V$ ratio may increase as DOC adsorbs onto detritus via exopolymers and is cemented by microbial activities (Paerl 1974); there is experimental evidence for a constant flow of polysaccharides and proteins into detritus at rates of $3 \% \mathrm{~d}^{-1}$ (Khaylov \& Finenko 1968). Thus the concurrent processes of production and consumption of detritus, termed the 'detritosphere' concept by Biddanda \& Pomeroy (1988), may act to minimize changes in the 
$\mathrm{C}: \mathrm{V}$ ratio. It is also worth noting that the direction and magnitude of nitrogen flow in detritus may not be the same as those of carbon (Biddanda \& Riemann 1992), which may contribute to the lower regression coefficients observed here for nitrogen versus carbon (Fig. 2), and the scatter in the relationship between detrital carbon and nitrogen (Fig. 3). The variance in $\mathrm{C}: \mathrm{V}$ and $\mathrm{NV}$ of detritus and its causes are currently under investigation.

The capability to quantify both plankton and detritus is potentially significant from several perspectives. First, the presence of detritus confounds attempts to estimate phytoplankton carbon in natural plankton communities: in fact, high total POC:chl a ratios in situ are considered indicative of contamination by detrital carbon. The ability to independently quantify detritus would yield more accurate estimates of phytoplankton carbon, an outstanding problem in phytoplankton ecology (Banse 1977). In this regard, it should also improve algorithms to convert satellite data into ocean pigment budgets (Garver et al. 1994) and estimates of phytoplankton growth rates, e.g. '...specific growth rates of phytoplankton cannot be accurately estimated from beam attenuation until the relative contributions of phytoplankton, microheterotrophs, and detritus are resolved' (Cullen et al. 1992). Second, detrital carbon, while generally comprising lower $\mathrm{C}: \mathrm{N}$ ratios than phytoplankton, can enhance survival and reproduction of zooplankton (Heinle \& Flemer 1975, Roman 1984). In the Peruvian upwelling zone, for example, detrital carbon was estimated to provide $40 \%$ of the diet of heterotrophs (Lebedeva et al. 1982). Third, because detritus is nonliving and therefore lacks behavioral and physiological responses to environmental stimuli, its carbon pool may not follow the same flux or transformation routes as does plankton carbon, e.g. phytoplankton ingestion by zooplankton, mass sedimentation of diatoms. For example, living phytoplankton were estimated to contribute only $1 \%$ of offshore POC flux during the Shelf Edge Exchange Process (SEEP) studies (Falkowski et al. 1994). Thus, budgeting detrital carbon as distinct from plankton carbon may yield valuable insights into the structure and operation of planktonic ecosystems.

Acknowledgements. Several colleagues supported the technical developments described here, especially $K$. Kutz of Georgia Instruments, Inc. (Atlanta, Georgia); J. Kesterson and M. Richardson of Vaytek, Inc. (Fairfield, Iowa); J. Jones of Olympus America, Inc. (Atlanta); and R. Farrigan and G. Tindal. Colleagues from the Brookhaven National Laboratory collected the CHN samples at sea and generously provided the POC, PON, and chlorophyll data. Financial support from the U.S. Department of Energy (contract \#DE-FG0292ER61419) and the Skidaway Institute of Oceanography is gratefully acknowledged. D. Peterson prepared the manuscript and A. Boyette drafted the figures.

\section{LITERATURE CITED}

Agard DA, Hiraoka Y, Shaw P, Sedat JW (1989) Fluorescence microscopy in three dimensions. Methods Cell Biol 30: $353-377$

Alldredge AL. Gotschalk CC (1989) Direct observations of the mass flocculation of diatom blooms: characteristics, settling velocities, and formation of diatom aggregates. Deep Sea Res 36:159-171

Altabet MA (1990) Organic C, N, and stable isotopic composition of particulate matter collected on glass-fiber and aluminum oxide filters. Limnol Oceanogr 35:902-909

Andersson A, Rudehall A (1993) Proportion of plankton biomass in particulate organic carbon in the northern Baltic Sea. Mar Ecol Prog Ser 95:133-139

Arndt-Jovin DJ (1991) Digital microscopy and image analysis: where does it impact on oceanography? In: Demers S (ed) Particle analysis in oceanography, NATO ASI Series, Vol G27. Springer-Verlag, Berlin, p 31-38

Arndt-Jovin DJ, Jovin TM (1989) Fluorescence labelling and microscopy of DNA. In: Taylor DL, Wang Y (eds) Fluorescence microscopy of living cells in culture, Part B. Quantitative fluorescence microscopy-imaging and spectroscopy, Academic Press, New York, p 417-448

Banse K (1977) Determining the carbon-to-chlorophyll ratio of natural phytoplankton. Mar Biol 41:199-212

Biddanda BA (1988) Microbial aggregation and degradation of phytoplankton-derived detritus in seawater. II. Microbial metabolism. Mar Ecol Prog Ser 42:89-95

Biddanda BA, Pomeroy LR (1988) Microbial aggregation and degradation of phytoplankton-derived detritus in seawater. I. Microbial succession. Mar Ecol Prog Ser 42:79-88

Biddanda B, Riemann F (1992) Detrital carbon and nitrogen relation, examined by degrading cellulose. PSZN I: Mar Ecol 13:271-283

Børsheim KY, Bratbak G (1987) Cell volume to cell carbon conversion factors for a bacterivorous Monas sp. enriched from seawater. Mar Ecol Prog Ser 36:171-175

Bratbak G, Dundas I (1984) Bacterial dry matter content and biomass estimations. Appl Environ Microbiol 48:755-757

Bundy $\mathrm{MH}$, Paffenhöfer GA (1993) Innervation of copepod antennules investigated using laser scanning confocal microscopy. Mar Ecol Prog Ser 102:1-14

Caron DA, Dam HG, Kremer P, Lessard EJ, Madin LP, Malone TC, Napp JM, Peele ER, Roman MR, Youngbluth MJ (1995) The contribution of microorganisms to particulate carbon and nitrogen in surface waters of the Sargasso Sea near Bermuda. Deep Sea Res I 42:943-972

Castleman KR (1979) Digital image processing. Prentice-Hall, Inc, Englewood Cliffs, NJ

Cullen JJ, Lewis MR, Davis CO, Barber RT (1992) Photosynthetic characteristics and estimated growth rates indicate grazing is the proximate control of primary production in the equatorial Pacific. J Geophys Res C1 97:639-654

Decho AW (1990) Microbial exopolymer secretions in ocean environments: their role(s) in food webs and marine processes. Oceanogr Mar Biol A Rev 28:73-153

Eppley RW, Chavez FP, Barber RT (1992) Standing stocks of particulate carbon and nitrogen in the equatorial Pacific at $150^{\circ}$ W. J Geophys Res C1 97:655-661

Falkowski PG, Biscaye PE, Sancetta C (1994) The lateral flux of biogenic particles from the eastern North American continental margin to the North Atlantic Ocean. Deep Sea Res II 40:583-602

Friedman MM, Strickler JR (1975) Chemoreceptors and feeding in calanoid copepods (Arthropoda: Crustacea). Proc Natl Acad Sci USA 72:4185-4188 
Garver SA, Siegel DA, Mitchell BG (1994) Variability in nearsurface particulate absorption spectra: what can a satellite ocean color imager see? Limnol Oceanogr 39:1349-1367

Gassmann G, Gillbricht M (1982) Correlations between phytoplankton, organic detritus, and carbon in North Sea waters during the Fladenground Experiment (FLEX '76) Helgoländer Meeresunters 35:253-262

Gibson SF, Lanni F (1990) Measured and analytical point spread functions of the optical microscope for use in 3-D optical serial sectioning microscopy. In: Herman B, Jacobsen, $\mathrm{K}$ (eds) Optical microscopy for biology. Wiley-Liss, Inc., New York, p 109-118

Gordon DC Jr (1970) A microscopic study of organic particles in the North Atlantic Ocean. Deep Sea Res 17:175-185

Haugland RP (1992) Molecular probes - handbook of fluorescent probes and research chemicals. Molecular Probes, Eugene, OR

Heinle DR, Flemer DA (1975) Carbon requirements of a population of the estuarine copepod Eurytemora affinis. Mar Biol 31:235-247

Hiraoka Y, Sedat JW, Agard DA (1990) Determination of three-dimensional imaging properties of a light microscope system. Biophys j 57:325-333

Khaylov KM, Finenko ZZ (1968) Interaction of detritus with high-molecular-weight components of dissolved organic matter in seawater. Oceanology 8:776-785

Kroer N (1994) Relationships between biovolume and carbon and nitrogen content of bacterioplankton. FEMS Microb Ecol 13:217-224

Lebedeva LP, Vinogradov MY, Shushkina EA, Sazhin AF (1982) Estimating the rates of detritus formation in marine planktonic communities. Oceanology 22:483-488

Lee BG, Fisher NS (1992) Degradation and elemental release rates from phytoplankton debris and their geochemical implications. Limnol Oceanogr 37:1345-1360

Lenz $J$ (1977) On detritus as a food source for pelagic filterfeeders. Mar Biol 41:39-48

Lessard E (1991) The trophic role of heterotrophic dinoflagellates in diverse marine environments. Mar Microb Food Webs 5:49-58

Mel'nikov IA (1974) Use of histochemical reagents to determine the biochemical composition of detritus. Oceanology $14: 922-926$

Michaels AF, Silver M (1988) Primary production, sinking fluxes, and the microbial food web. Deep Sea Res 35: 473-490

Montagnes DJS, Berges JA, Harrison PJ, Taylor FJR (1994) Estimating carbon, nitrogen, protein, and chlorophyil a from volume in marine phytoplankton. Limnol Oceanogr 39:1044-1060

Paerl HW (1974) Bacterial uptake of dissolved organic matter in relation to detrital aggregation in marine and freshwater systems. Limnol Oceanogr 19:966-972

Parker BC, Diboll AG (1966) Alcian stains for histochemical jocaijzation of acid and suilated poiysaccharides in aigae. Phycologia 6:36-46

Passow U, Alldredge AL, Logan BE (1994) The role of particulate carbohydrate exudates in the flocculation of diatom blooms. Deep Sea Res I 41:335-357

Pomeroy LR (1979) Secondary production mechanisms of continental shelf communities. In: Livingston RJ (ed) Ecological processes in coastal and marine ecosystems. Plenum Press, New York, p 163-1.86

Pomeroy LR (1980) Detritus and its role as a food source. In: Barnes RK, Mann $\mathrm{KH}$ (eds) Fundamentals of aquatic ecosystems. Blackwell Sci. Publ., London, p 84-102

Putt $M$, Stoecker DK (1989) An experimentally determined carbon:volume ratio for marine 'oligotrichous' ciliates from estuarine and coastal waters. Limnol Oceanogr 34: $1097-1103$

Reiswig HM (1972) The spectrum of particulate organic matter of shallow-bottom boundary waters of Jamaica. Limnol Oceanogr 17:341-348

Rigaut JP, Carvajal-Gonzalez S, Vassy J (1992) Confocal image cytometry-quantitative analysis of three-dimensional images obtained by confocal scanning microscopy. In: Häder DP (ed) Image analysis in biology. CRC Press, London, p 109-133

Roman MR (1984) Utilization of detritus by the copepod, Acartia tonsa. Limnol Oceanogr 29:949-959

Russ JC (1995) The image processing handbook, 2nd edn. CRC Press, London

Seiki T, Date E, Izawa H (1991) Decomposition characteristics of particulate organic matter in Hiroshima Bay. J Oceanogr Soc Japan 47:207-220

Sharp JH (1974) Improved analysis for particulate organic carbon and nitrogen from seawater. Limnol Oceanogr 19: 984-989

Shotton DM (1989) Confocal scanning optical microscopy and its applications for brological specimens. J Cell Sc1 94: $175-206$

Sieracki ME, Reichenbach S, Webb KW (1989a) An evaluation of automated threshold detection methods for accurate sizing of microscopic fluorescent cells by image analysis. Appl Environ Microbiol 55:2762-2772

Sieracki ME, Verity PG, Stoecker DK (1993) Plankton community response to sequential silicate and nitrate depletion during the 1989 North Atlantic spring bloom. Deep Sea Res II 40:213-226

Sieracki ME, Viles CL, Webb KW (1989b) Algorithm to estimate cell biovolume using image analyzed microscopy. Cytometry 10:551-557

Smetacek V. Hendrikson P (1979) Composition of particulate organic matter in Kiel Bight in relation to phytoplankton succession. Oceanol Acta 2:287-298

Taniguchi A, Takeda Y (1988) Feeding rate and behavior of the tintinnid ciliate Favella taraikaensis observed with a high speed VTR system. Mar Microb Food Webs 3:21-34

Taylor JK (1990) Statistical techniques for data analysis. Lewis Publishers, Inc., Cheisea, MI

Taylor P, Lappi S (1975) Interaction of fluorescence probes with acetylcholinesterase. The site and specificity of propidium binding. Biochemistry 14:1989-1997

Verity PG, Langdon C (1984) Relationships between lorica volume, carbon, nitrogen, and ATP content of tintinnids in Narragansett Bay. J Plankton Res 6:859-868

Verity PG, Paffenhöfer GA, Wallace D, Sherr E, Sherr B (1996) Composition and biomass of plankton in spring on the Cape Hatteras shelf, with implications for carbon flux. Cont Shelf Res (in press)

Verity PG, Robertson CY, Tronzo CR, Andrews MG, Nelson JKk, Sieracki ME ( 19992 ) Rejationships between ceil voiume and the carbon and nitrogen content of marine photosynthetic nanoplankton. Limnol Oceanogr 37:1434-1.446

Verity PG, Sieracki ME (1993) Use of color image analysis and epifluorescence microscopy to measure plankton biomass In: Kemp PF, Sherr BF, Sherr EB, Cole JJ (eds) Handbook of methods in aquatic microbial ecology. Lewis Publ., London, p 327-338

Verity PG, Stoecker DK, Sieracki ME, Burkill PH. Edwards ES, Tronzo CR (1993) Abundance, biomass, and distribution of heterotrophic dinoflagellates during the North Atlantic spring bloom. Deep Sea Res II 40:227-244

Walsh ID, Gardner WD (1992) Comparison of large particle 
camera profiles with sediment trap fluxes. Deep Sea Res 39:1817-1834

Williams SC, Frischer M, Verity PG (1996) Distinguishing between metabolically active and inactive bacteria. EOS $76: 148$

Williams SC, Verity PG, Beatty $T$ (1995) A new stainung technique for dual identification of plankton and detritus in seawater. J Plankton Res 17:2037-2047

Responsible Subject Editor: J. Dolan, Villefranche-sur-Mer, France
Young IT (1989) Image fidelity: characterizing the imaging transfer function. In: Taylor DL, Wang Y (eds) Fluorescence microscopy of living cells in culture, Part B, Quantitative fluorescence microscopy - imaging and spectroscopy. Academic Press, New York, p 1-45

Zweifel UL, Hagström $\AA$ (1995) Total counts of marine bacteria include a large fraction of non-nucleoid containing bacteria (ghosts). Appl Environ Microb 61:2180-2185

Manuscript first received: September 18, 1995

Revised version accepted: November 29, 1995 